\title{
Formula-feeding reduces lactose digestive capacity in neonatal pigs
}

\author{
Thomas Thymann $^{1 *}$, Douglas G. Burrin ${ }^{2}$, Kelly A. Tappenden ${ }^{3}$, Charlotte R. Bjornvad ${ }^{1}$, Søren K. Jensen ${ }^{4}$ \\ and Per T. Sangild ${ }^{1}$ \\ ${ }^{1}$ Division of Human Nutrition, Royal Veterinary and Agricultural University, Rolighedsvej 30, DK-1958 Frederiksberg C, Denmark \\ ${ }^{2}$ US Department of Agriculture/Agricultural Research Service, Children's Nutrition Research Center, Houston, TX 77030, USA \\ ${ }^{3}$ Department of Food Science and Human Nutrition/Division of Nutritional Sciences, University of Illinois, Urbana, IL 61801, USA \\ ${ }^{4}$ Department of Animal Health, Welfare and Nutrition, Danish Institute of Agricultural Sciences, Tjele, DK-8830, Denmark
}

(Received 10 June 2005 - Revised 5 January 2006 - Accepted 6 January 2006)

\begin{abstract}
The intestine of newborn pigs develops rapidly during the first days postpartum. We investigated if feeding milk replacer (infant formula) as an alternative to colostrum has compromising effects on nutrient digestive function in the neonatal period. Nineteen piglets born at term were assigned to one of four treatments: (1) newborn controls; (2) natural suckling for $24 \mathrm{~h}$; (3) tube-fed formula for $24 \mathrm{~h}$; (4) tube-fed porcine colostrum for $24 \mathrm{~h}$. All three fed groups showed significant increases in small-intestinal and colonic weights, villous heights and widths, maltase and aminopeptidase A activities, and decreases in dipeptidylpeptidase IV activity, relative to newborn pigs. Following oral boluses of mannitol, lactose or galactose, formula-fed pigs showed significantly reduced plasma levels of mannitol and galactose compared with colostrum-fed pigs. Activity of intestinal inducible NO synthase and plasma levels of cortisol were significantly increased, whereas intestinal constitutive NO synthase and $\alpha$-tocopherol were decreased in formula-fed pigs compared with colostrum-fed pigs. Although formula-fed pigs only showed minor clinical signs of intestinal dysfunction and showed similar intestinal trophic responses just after birth, as those fed colostrum, lactose digestive capacity was markedly reduced. We conclude that formula-feeding may exert detrimental effects on intestinal function in neonates. Formula-induced subclinical malfunction of the gut in pigs born at term was associated with altered NO synthase activity and antioxidative capacity.
\end{abstract}

Formula-feeding: Lactose: Intestine: Neonatal pigs

The porcine gastrointestinal tract is relatively immature at birth and undergoes rapid developmental changes in the immediate postnatal period following the introduction of maternal colostrum (Sangild et al. 2000; Jensen et al. 2001). In situations where there is a shortage of maternal colostrum, feeding formula to the newborn (NB) is a relevant alternative to prevent starvation and maladaptation. Studies in premature infants indicate that part of the ingested lactose may pass unabsorbed to the colon (Watkins, 1982; Kien et al. 1987; Kien, 1996) which could cause over-fermentation and colon inflammation (Argenzio \& Meuten, 1991). In preterm infants and pigs, formula-feeding is associated with increased incidence of gut atrophy, malfunction and inflammation, possibly leading to severe lifethreatening intestinal disorders such as necrotising enterocolitis (Lucas \& Cole, 1990; Sangild et al. 2002a; McGuire \& Anthony, 2003). Although the gastrointestinal tract is most sensitive to formula-feeding in premature neonates (Sangild et al. 2002b), it cannot be excluded that also neonates born at term are negatively affected by formula-feeding. Therefore the objective of the present experiment was to study the immediate postnatal gastrointestinal responses to feeding a milk formula based on commercially available products used for newborn infants.

\section{Materials and methods \\ Animals and their treatment}

Two sows (Large White $\times$ Landrace; Research Station Sjælland III, Sjælland, Denmark) were induced with $0.7 \mathrm{ml}$ prostaglandin (Estrumat; Schering-Plough A/S, Farum, Denmark) on day 113 of gestation. On day 114, a total of nineteen newborn pigs were delivered and allocated to four experimental groups: newborn (NB; $n 4$; removed from sow 1 immediately after birth and killed for tissue collection approximately $3 \mathrm{~h}$ postpartum); suckling (SUCK; $n$ 4; allowed to suckle their mother (sow 1) for $24 \mathrm{~h}$ after birth); colostrum-fed (COL; $n$ 6; tube-fed porcine colostrum for $24 \mathrm{~h}$ ); formula-fed (FORM; $n$ 5; tube-fed formula for $24 \mathrm{~h}$ ). Pigs belonging to the COL and FORM groups were delivered by Caesarean section of sow 2 as described previously (Sangild et al. 2002b) and immediately transferred to heated infant incubators. The Caesarean section, which was introduced for logistic 
reasons, was performed approximately $24 \mathrm{~h}$ after induction with prostaglandin. Both sows and their fetuses therefore experienced the same endocrinological changes, making the route of delivery unimportant in regard to intestinal function in the newborns (Sangild et al. 2002c). While still anaesthetised from the Caesarean section, the pigs were fitted with an orogastric tube (6F; Portex, Hythe, Kent, UK) that was passed through an incision in the cheek, and secured to the skin with sutures. Additionally a catheter (4F; Portex) was inserted into the dorsal aorta via the transected umbilical artery and sutured to both the umbilicus and the skin on the lateral and dorsal parts of the body. Heparinised saline $(250 \mathrm{U} / \mathrm{ml})$ was kept in the vascular catheter to prevent coagulation. All procedures were approved by The National Committee on Animal Experimentation, Denmark. To evaluate any potential effects of catheterisation and tube-feeding, the SUCK group of pigs were not fitted with any catheters and thus served as a reference group to the COL group of pigs fed colostrum via a tube. Colostrum was obtained by manual milking of a number of different sows, no more than $6 \mathrm{~h}$ postpartum. The colostrum was extracted from all teats via manual stimulation of the mammary or via injection of 10 IU oxytocin (Oxytocin; Intervet, Skovlunde, Denmark) and pooled before storage at $-20^{\circ} \mathrm{C}$. The formula was mixed from commercially available products (SHS, Liverpool, UK) to reflect the macronutrient content of sows' milk, and thus formulated to meet the nutrient requirement for growth. The nutrient composition of the formula is shown in Table 1 (for values for the composition of colostrum, see Sangild \& $\mathrm{Xu}, 2004)$. Both diets were fed as a bolus $(15 \mathrm{ml} / \mathrm{kg}$ body weight) every $3 \mathrm{~h}$.

\section{Digestive and absorptive function}

Being a small but relatively low-digestible sugar alcohol, mannitol penetrates the mucosa both para-cellularly and trans-cellularly, and can be used as an arbitrary estimate of mucosal absorptive surface. As parameters of functional absorptive intestinal surface and lactose digestive capacity, we therefore monitored plasma levels of mannitol and galactose in response to oral boluses of mannitol, lactose and galactose respectively. At $18 \mathrm{~h}$ postpartum, all pigs from the COL and FORM groups were fasted for $6 \mathrm{~h}$ before being given a bolus $(15 \mathrm{ml} / \mathrm{kg}$ ) of a $10 \%$ lactose and $2 \%$ mannitol (Sigma, St Louis, MI, USA) solution through the orogastric tube. Blood samples were retrieved into heparinised syringes through the umbilical artery catheter at 0, 10, 20, 30, 40 and $70 \mathrm{~min}$. To further study galactose absorption capacity, a subsequent bolus $(15 \mathrm{ml} / \mathrm{kg}$ ) of a $5 \%$ galactose (Sigma, St Louis, USA) solution was given at 70 min before blood sampling at 80, 90, 100, 110 and $140 \mathrm{~min}$. All samples were centrifuged within $10 \mathrm{~min}\left(6000 \mathrm{~g} ; 4^{\circ} \mathrm{C} ; 2 \mathrm{~min}\right)$, and plasma isolated and frozen at $-20^{\circ} \mathrm{C}$ until further analysis. The in vivo test was also performed on the NB group. A fasting period was not included because they had not been fed. Blood samples were retrieved through a vascular catheter that was inserted into the transected umbilical artery and fixed transiently with cotton gauze around the umbilical cord. Including the $140 \mathrm{~min}$ of blood sampling, there was approximately a $3 \mathrm{~h}$ delay from birth to tissue collection.
Table 1. Macronutrient composition of formula (per litre)*

\begin{tabular}{|c|c|}
\hline Component & Content \\
\hline Energy (kJ) & 4150 \\
\hline Protein $(\mathrm{g})$ & 63.9 \\
\hline Carbohydrates (g) & $46 \cdot 9$ \\
\hline Sugars $(g)$ & 9 \\
\hline Fat $(g)$ & $61 \cdot 3$ \\
\hline Saturated fat $(\mathrm{g})$ & $44 \cdot 3$ \\
\hline Monounsaturated fat (g) & $9 \cdot 7$ \\
\hline Polyunsaturated fat (g) & 3.7 \\
\hline Vitamin A ( $\mu$ g retinol equivalents) & 422 \\
\hline Vitamin D $(\mu \mathrm{g})$ & $6 \cdot 8$ \\
\hline Vitamin E (mg $\alpha$-tocopherol equivalents) & $2 \cdot 6$ \\
\hline Vitamin C (mg) & 32 \\
\hline Vitamin $\mathrm{K}(\mu \mathrm{g})$ & $16 \cdot 8$ \\
\hline Vitamin $B_{1}(\mathrm{mg})$ & 0.31 \\
\hline Vitamin $B_{2}(\mathrm{mg})$ & 0.48 \\
\hline Niacin (mg) & $3 \cdot 6$ \\
\hline Vitamin $\mathrm{B}_{6}(\mathrm{mg})$ & 0.41 \\
\hline Folacin $(\mu \mathrm{g})$ & $30 \cdot 4$ \\
\hline Vitamin $B_{12}(\mu \mathrm{g})$ & 1 \\
\hline Biotin $(\mu \mathrm{g})$ & $20 \cdot 8$ \\
\hline Pantothenic acid (mg) & $2 \cdot 12$ \\
\hline $\mathrm{Na}(\mathrm{mg})$ & 345 \\
\hline $\mathrm{K}(\mathrm{mg})$ & 728 \\
\hline $\mathrm{Cl}(\mathrm{mg})$ & 245 \\
\hline $\mathrm{Ca}(\mathrm{mg})$ & 513 \\
\hline$P(\mathrm{mg})$ & 392 \\
\hline $\mathrm{Mg}(\mathrm{mg})$ & 65 \\
\hline $\mathrm{Fe}(\mathrm{mg})$ & $5 \cdot 6$ \\
\hline $\mathrm{Cu}(\mathrm{mg})$ & 304 \\
\hline $\mathrm{Zn}(\mathrm{mg})$ & 4 \\
\hline $\mathrm{Mn}(\mathrm{mg})$ & 0.3 \\
\hline $\mathrm{I}(\mu \mathrm{g})$ & $37 \cdot 6$ \\
\hline $\mathrm{Mb}(\mu \mathrm{g})$ & 11.4 \\
\hline Se $(\mu g)$ & $8 \cdot 8$ \\
\hline $\mathrm{Cr}(\mu \mathrm{g})$ & 8 \\
\hline Choline (mg) & 40 \\
\hline Inositol (mg) & 80 \\
\hline L-Carnitine (mg) & 8 \\
\hline Taurine (mg) & 24 \\
\hline
\end{tabular}

${ }^{*}$ All concentrations were calculated from declared values of included ingredients (SHS International, Liverpool, UK). Each litre of formula contained $80 \mathrm{~g}$ Pepdite $2+, 70 \mathrm{~g}$ Maxipro and $75 \mathrm{~g}$ Liquigen. Major ingredients in the formula were: hydrolysed dried maize syrup (maltodextrins); bovine whey protein; hydrolysed meat- and soya-protein; maize- and coconut-oil.

\section{Tissue collection}

Following the in vivo blood collections, the piglets were anaesthetised (Zoletil 50, zolazepam/tiletamin; Boehringer Ingelheim, Copenhagen, Denmark) and subsequently euthanised with an intracardiac injection of sodium pentobarbitone. Individual weights of the heart, lungs, liver, kidneys, adrenals, spleen, stomach, small intestine and colon were recorded. Length of the small intestine was recorded, and whole-wall intestinal tissue samples were taken at sites $17 \%$ (proximal), $50 \%$ (middle) and $83 \%$ (distal) along the small intestine. A sample of colon tissue was taken from its middle part. Each sample was excised and frozen in liquid $\mathrm{N}_{2}$ within $5 \mathrm{~min}$ after euthanisation. Finally, $10 \mathrm{~cm}$ segments from the proximal, middle and distal parts of the jejunum were isolated and slit along their lengths for determination of circumference and percentage of mucosa. Mucosa was isolated by gentle scraping, and its weight proportion was determined on both wet-matter and DM bases as described previously (Sangild et al. 2002b). 


\section{Biochemical analyses}

Concentrations of mannitol in plasma were analysed spectrophotometrically using a Cobas Mira analyser (Roche Products, Welwyn Garden City, Herts, UK). The reaction between mannitol and NAD (Boehringer Mannheim, Darmstadt, Germany) was catalysed by D-mannitol dehydrogenase, yielding NADH which was detected spectrophotometrically at $340 \mathrm{~nm}$ as an end-point analysis (Blood et al. 1991). Likewise, for analysis of galactose, deproteinised samples of plasma were added to NAD on a microtitre plate. Subsequently, galactose dehydrogenase (Boehringer Mannheim, Darmstadt, Germany) was added to the well, catalysing the reaction between plasma galactose and NAD. The amount of NADH formed from the reaction was detected spectrophotometrically at $340 \mathrm{~nm}$ (Kurz \& Wallenfels, 1974).

Activities of lactase-phloridzin (EC 3.2.1.23-62), sucraseisomaltase ( $E C$ 3.2.1.48-10), maltase-glucoamylase ( $E C$ 3.2.1.20), dipeptidylpeptidase IV (EC 3.4.14.5), aminopeptidase $\mathrm{N}$ (EC 3.4.11.2) and aminopeptidase A (EC 3.4.11.7) in homogenates of intestinal tissue (proximal, middle, distal, and colon) were determined spectrophotometrically using lactose, sucrose, maltose, glycyl-L-prolin-4-nitroanilide, L-alanine-4nitroanilide, and $\alpha$-L-glutamic acid 4-nitroanilide respectively, as substrates, in accordance with a previously established protocol (Sangild et al. 1995).

Measurement of inducible NO synthase (iNOS) and total NO synthase (tNOS) activity was performed according to the methods established by Wu et al. (1999) and Guan et al. (2003). Briefly, tissue homogenates from the proximal small intestine of COL and FORM pigs were used to measure the kinetics of the conversion of $\mathrm{L}-\left[{ }^{14} \mathrm{C}\right]$ arginine into $\mathrm{L}-\left[{ }^{14} \mathrm{C}\right]$ citrulline and NO. The radioactivity of $\mathrm{L}-\left[{ }^{14} \mathrm{C}\right]$ citrulline was measured by a Beckman liquid scintillation system (LS 5000 TD; Beckman Instruments, Fullerton, CA, USA). Constitutive NOS (cNOS) was calculated as the difference between tNOS and iNOS, and values were expressed as nmol NO/min per $\mathrm{g}$ tissue.

Sodium GLUT-1 (SGLT-1) and GLUT-2 protein abundance was determined in tissue homogenates as described by Tappenden \& McBurney (1998). Western blot analysis for SGLT-1 and GLUT-2 protein was performed using polyclonal antibodies detecting the 73 and $60 \mathrm{kDa}$ bands, respectively (Chemicon International, Temecula, CA, USA). Densitometry of SGLT-1 and GLUT-2 protein abundance was performed using Kodak ID Image Analysis Software (version 3.5.4; Eastman Kodak Company, Rochester, NY, USA). To avoid relating transporter proteins to the amount of tissue protein derived from absorption of colostral $\mathrm{Ig}$, the densitometry readings were related to tissue weight rather than tissue protein concentration.

For intestinal morphology, a distal jejunal tissue sample was fixed in paraformaldehyde and $70 \%$ ethanol and imbedded in paraffin. Slices of $3 \mu \mathrm{m}$ were cut and stained with haematoxylin and eosin. Villous height, villous width and crypt depth were measured on fifteen well-oriented villi and crypts in each sample, using a light microscope (Orthoplane, Leitz, Germany) and NIH Image J software (version 1.22c; National Institutes of Health, Bethesda, MD, USA). Cortisol concentrations in plasma were determined by ELISA (Biomar Diagnostics, Marburg, Germany), and vitamin E levels were analysed by HPLC after saponification and extraction as described by Jensen et al. (1999).

\section{Statistical evaluation}

The effects of dietary treatments on organ weights, enzyme activity, cortisol, vitamin E, and morphology were evaluated by the MIXED procedure of the SAS software package version 8.2 (SAS Institute Inc., Cary, NC, USA) using treatment and intestinal region as fixed variables and pig as random variable. Data on lactose digestive capacity and galactose and mannitol absorption were analysed as repeated measures using a Gaussian model of spatial correlation in the MIXED procedure of SAS. Probability levels below 0.05 were considered significant. Differences between individual treatment means were tested using the PDIFF option of SAS.

\section{Results}

At the time of tissue collection, all of the FORM group, but none of the COL pigs, showed a mild yellow diarrhoea but appeared clinically healthy otherwise. Moreover, undigested material was observed in the colon of the FORM group, but not in the COL pigs. Small-intestinal relative weight, total serosal surface area, circumference, percentage of wet mucosa, villous dimensions and relative colon weights were similar between the FORM and COL $(P>0 \cdot 15)$ groups but significantly higher compared with the NB group $(P<0.05)$ (Table 2). Moreover, the relative weights of the heart, lungs, liver, kidneys, adrenals and spleen were not significantly different between the FORM and COL groups $(P>0.05$; data not shown). Finally, pigs in the SUCK group were not different from pigs fed colostrum via a tube in any of these parameters.

\section{Digestive and absorptive capacity}

Plasma galactose in response to an oral bolus of lactose was markedly reduced in the FORM group compared with the COL and NB groups $(P<0 \cdot 0001$; Fig. 1(A)). Increments in plasma galactose in response to an oral galactose bolus showed a similar markedly reduced level in the FORM group compared with the COL group $(P<0 \cdot 01$; Fig. 1(B)). As a further indication of gut malabsorption, there were significant differences in plasma mannitol levels between all fed groups $(P<0.001$; Fig. 1 (C) $)$ in response to an oral bolus of mannitol.

\section{In vitro measurements of digestive enzyme activity}

Regional and treatment differences were present, in that lactase and maltase activities in the proximal part of the small intestine of the COL group of pigs were significantly higher than in the other groups (Fig. 2). Moreover, mid and distal maltase activities in all three fed groups increased significantly compared with the NB group. Likewise, there appeared to be a general increase in small-intestinal aminopeptidase A activity in all fed groups compared with the NB group, although this was only significant in the proximal and middle regions. In general, activity of all enzymes in the colon was equally low in all four treatment groups. Sucrase activity was low 
Table 2. Body weight at kill, weights of digestive organs relative to body weight and dimensions of the small intestine of pigs at 0 or $24 \mathrm{~h}$ postpartum

(Mean values with their standard errors)

\begin{tabular}{|c|c|c|c|c|c|c|}
\hline \multirow[t]{2}{*}{ Group... } & \multicolumn{2}{|c|}{ NB } & \multicolumn{2}{|c|}{ FORM } & \multicolumn{2}{|c|}{ COL } \\
\hline & Mean & SEM & Mean & SEM & Mean & SEM \\
\hline Piglets (n) & \multicolumn{2}{|c|}{4} & \multicolumn{2}{|c|}{5} & \multicolumn{2}{|c|}{6} \\
\hline Body weight at kill (g) & $913^{\mathrm{a}, \mathrm{c}}$ & 120 & $1358^{\mathrm{b}}$ & 138 & $1378^{\mathrm{b}}$ & 135 \\
\hline Stomach $(\mathrm{g} / \mathrm{kg})$ & 4.90 & 0.40 & 4.59 & 0.20 & 4.79 & 0.38 \\
\hline Small intestine $(\mathrm{g} / \mathrm{kg})$ & $20 \cdot 24^{\mathrm{a}}$ & 0.52 & $34.25^{b}$ & 2.88 & $32 \cdot 84^{\mathrm{b}}$ & 2.34 \\
\hline Colon $(\mathrm{g} / \mathrm{kg})$ & $4.48^{\mathrm{a}}$ & 0.23 & $5 \cdot 78^{b}$ & 0.45 & $6 \cdot 25^{\mathrm{b}}$ & 0.84 \\
\hline Total serosal surface $\left(\mathrm{cm}^{2}\right)$ & $196^{\mathrm{a}}$ & 13 & $418^{b}$ & 54 & $348^{b}$ & 63 \\
\hline Circumference $(\mathrm{mm})$ & $7 \cdot 2^{\mathrm{a}}$ & 0.3 & $11.5^{\mathrm{b}}$ & 0.4 & $10 \cdot 2^{b}$ & 0.6 \\
\hline Dry mucosa (\%) & $65 \cdot 9^{\mathrm{a}}$ & 1.5 & $80 \cdot 6^{\mathrm{b}}$ & 2.5 & $81 \cdot 2^{\mathrm{b}}$ & $2 \cdot 7$ \\
\hline Villus height $(\mu \mathrm{m})$ & $662^{\mathrm{a}}$ & 22 & $968^{\mathrm{b}}$ & 140 & $1009^{b}$ & 109 \\
\hline Villus width $(\mu \mathrm{m})$ & $78^{\mathrm{a}}$ & 4 & $90^{\mathrm{b}}$ & 3 & $96^{b}$ & 5 \\
\hline Crypt depth $(\mu \mathrm{m})$ & 85 & 4 & 92 & 6 & 84 & 3 \\
\hline
\end{tabular}

NB, newborn (0h); FORM, formula-fed (24h); COL, colostrum-fed (24h).

$\mathrm{a}, \mathrm{b}, \mathrm{c}$ Mean values within a row with unlike superscript letters were significantly different $(P<0.05)$.

and showed large variation in all regions, and there were no significant treatment effects.

\section{Plasma cortisol}

Cortisol was significantly lower in pigs from the COL group compared with the FORM and NB groups, whereas the difference between the FORM and NB groups was not significant (Fig. 3).

\section{$\alpha$-Tocopherol}

NB pigs had only very limited amounts of $\alpha$-tocopherol in the tissue, whereas pigs in the FORM and COL groups had significantly more. Additionally there was a large significant difference between the FORM and COL groups, in that the FORM group contained less than half of that in the COL group (Fig. 3).

\section{Nitric oxide synthase}

The activity of iNOS was significantly higher in the FORM group compared with the COL group $(+280 \%)$. In contrast, pigs in the FORM group showed no detectable cNOS activity, whereas pigs in the COL group had a significant and markedly higher cNOS activity (Fig. 3).

\section{Sodium glucose transporter-1 and glucose transporter-2}

To supplement the observations on in vivo absorptive function, protein abundance of apical and basal membrane transporters (SGLT-1 and GLUT-2) was measured. Based on Western blots, the abundance of these key transporters did not seem to be significantly different between any treatment groups (Fig 3).

\section{Discussion}

The switch from parenteral to enteral feeding at birth marks the onset of major developmental changes in the intestine
(Sangild et al. 2000). Neonatal infants and pigs are commonly fed milk formulas when breast-feeding or provision of maternal colostrum is not possible. The formula must not only meet the quantitative nutritional requirements of the newborn but also, like colostrum, induce gut maturation in the immediate postnatal period. In the present study, formula mimicked the effects of colostrum on growth of all visceral organs including the gastrointestinal tract, in addition to providing the same intestinal morphological changes as those induced by colostrum. Studies with pigs born premature show that immaturity may affect the response to enteral feeding (Sangild et al. 2002b) and that feeding formula to premature pigs or infants can be associated with severe detrimental effects on gut structure and function (Neu, 1996; Sangild et al. 2002a). However, the clinical consequences of feeding formula do not appear to be as critical for term pigs, relative to preterm pigs (Jensen et al. 2001), because pigs fed formula in the present experiment showed only minor clinical symptoms of gastrointestinal disorder. Nevertheless, at the functional level, in vivo lactose digestive capacity was markedly reduced in FORM pigs indicating malfunction of the gut. The postnatal development of organ mass, intestinal morphology and enzyme activities were similar and corresponded well with results of other studies (Sangild et al. 2000). The regional differences in maltase activity between the COL and SUCK groups of pigs may be explained by intake of different amounts of colostrum. Consistent with the observations of malabsorption, a formula-like solution was observed in the colon of the FORM pigs suggesting that either small-intestinal digestive capacity had been exceeded or there was too little contact between the diet and the mucosa. It is possible that formula-feeding may have altered the postnatal development of intestinal motility as indicated by preliminary studies on duodenal and colonic tissue contractibility patterns in FORM and COL pigs (Sangild et al. 2003). Several mechanisms at the cellular level could also potentially explain the differences in lactose digestibility. First, the nearly complete lack of galactose absorption in response to oral lactose may suggest insufficient lactase activity in the FORM pigs. Although overall small-intestinal lactase activity was not different among diet groups in the 

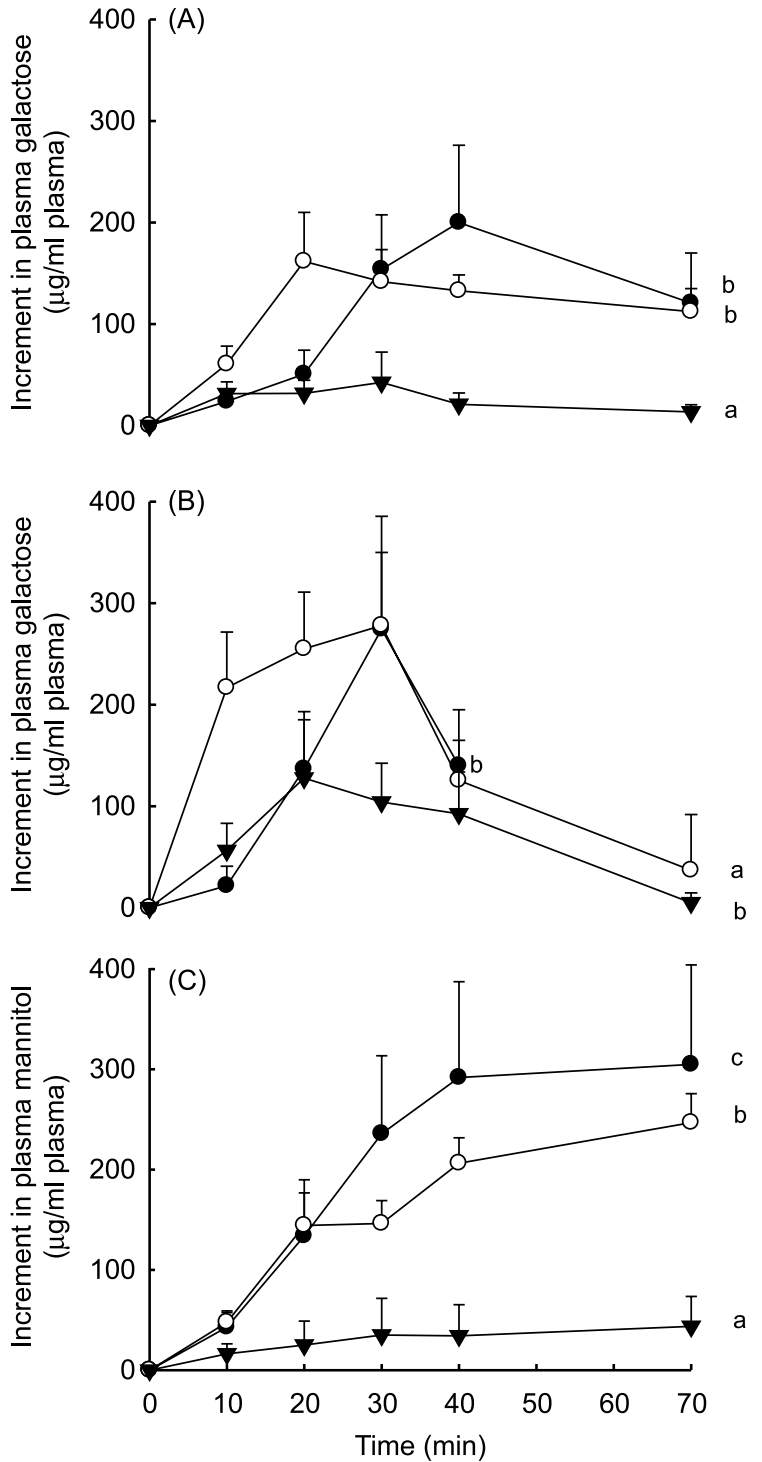

Fig. 1. Increments in plasma levels of galactose (A, B) and mannitol (C) measured over $70 \mathrm{~min}$ in response to oral boluses of lactose $(10 \%$ lactose solution $(15 \mathrm{ml} / \mathrm{kg}) ; A)$, galactose $(5 \%$ galactose solution $(15 \mathrm{ml} / \mathrm{kg}) ; B)$ and mannitol (2\% mannitol solution $(15 \mathrm{ml} / \mathrm{kg}) ; \mathrm{C})$ in neonatal pigs. Values are means, with their standard errors represented by vertical bars. (--), Newborn control; $(-\bigcirc-)$, colostrum-fed; $(-\nabla-)$, formula-fed. ${ }^{\mathrm{a}, \mathrm{b}, \mathrm{c}}$ Unlike letters represent significanlty different treatments $(P<0.01)$.

present and other studies (Zang et al. 1998), the lower proximal lactase activity in the FORM group may be more important for overall lactose digestibility than total smallintestinal lactase activity. However, the apparent lack of lactose hydrolysis in the FORM pigs still needs further investigation. Second, the formula-induced reduction in plasma galactose increment in response to a bolus of galactose indicates either increased hepatic cleareance or increased enterocyte first-pass metabolism, whereas abundance of membrane transporters seemed to be unaffected by formula-feeding. First-pass metabolism of sugars and amino acids in enterocytes has been shown in both lambs (Kaempf et al. 1990) and pigs (Stoll et al. 1998, 1999). The use of galactose as metabolic fuel in enterocytes may depend on availability of other more preferred substrates such as glucose, glutamate and glutamine (Stoll et al. 1998, 1999). The degree of firstpass enterocyte galactose metabolism may therefore be altered by dietary treatments, since formula and colostrum may contain somewhat different amounts of these specific nutrients.

The mechanisms behind gut malfunction in the FORM pigs may also include the altered NOS activity. NO is synthesised from L-arginine by three NOS isoforms, i.e. endothelial, neuronal and iNOS. The two isoforms endothelial and neuronal collectively represent cNOS activity and represent NO synthesis at physiological levels which is believed to be essential for maintenance of normal gut function and integrity (Kubes, 2000; Kubes \& McCafferty, 2000). The role of iNOS is less well understood but it seems that iNOS often synthesises NO at pathologically high levels, inducing detrimental inflammatory effects on the intestine (Kubes, 2000; Kubes \& McCafferty, 2000). Interestingly, in the present study iNOS was markedly elevated and cNOS completely absent in the FORM $v$. COL pigs. It has been suggested that iNOS may exert its detrimental effect through the production of potent radicals such as peroxynitrite (Kubes \& McCafferty, 2000). Higher production of radicals in the FORM pigs may have consumed some of the antioxidative buffer capacity of the diet. Additionally, FORM piglets consumed only half the amount $(2.6 \mathrm{mg} / \mathrm{l})$ of $\alpha$-tocopherol compared with COL piglets (approximately 4-8 mg/l; Mahan, 1991), and this may be the major explanation why tissue $\alpha$-tocopherol levels were less than half those of the COL pigs. Finally, the antioxidative properties of the diets may be different due to differences in bioavailability and biological activity of the vitamin $\mathrm{E}$ ingested. In artificial diets, including the present formula, vitamin $\mathrm{E}$ is often present in the form of all-rac- $\alpha$-tocopheryl acetate, which has to be hydrolysed to the active form ( $\alpha$-tocopherol) by carboxyl ester hydrolase in the small intestine. Since neonatal pigs do not express high levels of caboxyl ester hydrolase activity (Lauridsen et al. 2003), part of the observed difference between FORM and COL pigs may also be caused by different activity of the $\alpha$-tocopherol present in the diets. The sub-optimal physiological situation caused by formula-feeding was also observed as an increase in plasma levels of the stress hormone cortisol, which was higher in the FORM group compared with the COL group. The higher level of plasma cortisol in the FORM pigs may indicate adaptation to a sub-optimal situation. The even higher level in newborns is more likely a normal peak in cortisol associated with the birth process, and is believed to be important for postnatal gut development (Trahair \& Sangild, 1997).

In conclusion, formula-feeding to newborn term pigs was associated with only minor symptoms of gastrointestinal dysfunction and it mimicked many of the short-term postnatal trophic effects observed in COL pigs. Nevertheless, the present study demonstrates that formula-feeding compromises intestinal digestive function, at least at the subclinical level. Formula-feeding, as the sole source of nutrition, may lead to gut dysfunction in the slightly longer term, even in term neonates, and the effects may be even more pronounced if intestinal maturity is compromised by factors such as preterm birth and in utero growth retardation. 

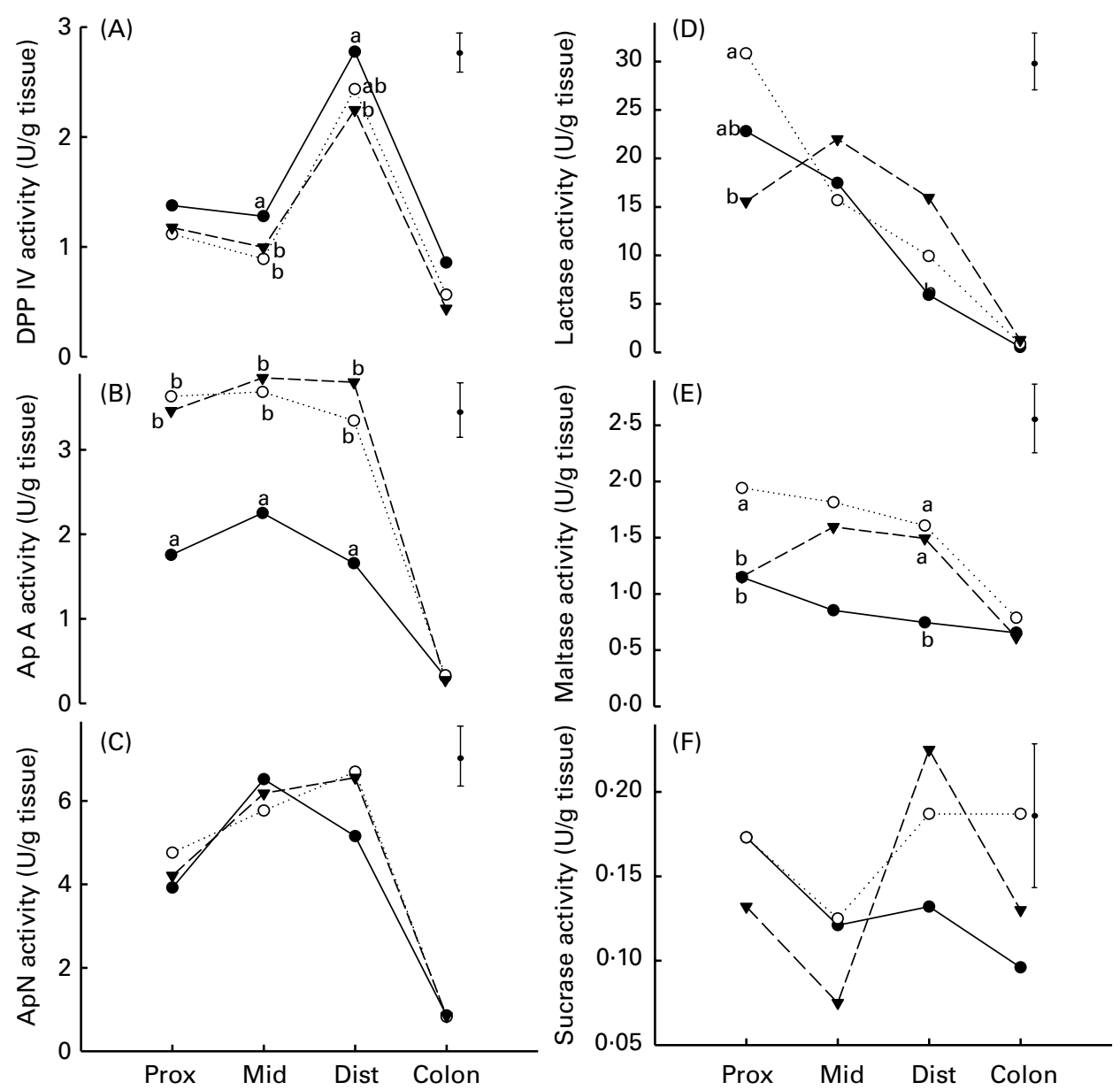

Fig. 2. Dipeptidylpeptidase IV (DPP IV; A), aminopeptidase A (ApA; B), aminopeptidase N (ApN; C), lactase (D), maltase (E) and sucrase (F) activities in three smallintestinal regions (proximal (Prox), mid and distal (Dist)) and in the colon of neonatal pigs. Values are least square means. The bars in the upper-right corner of each panel

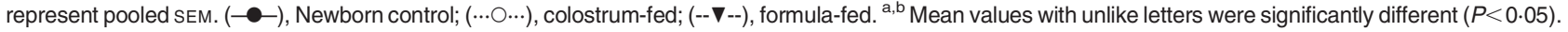
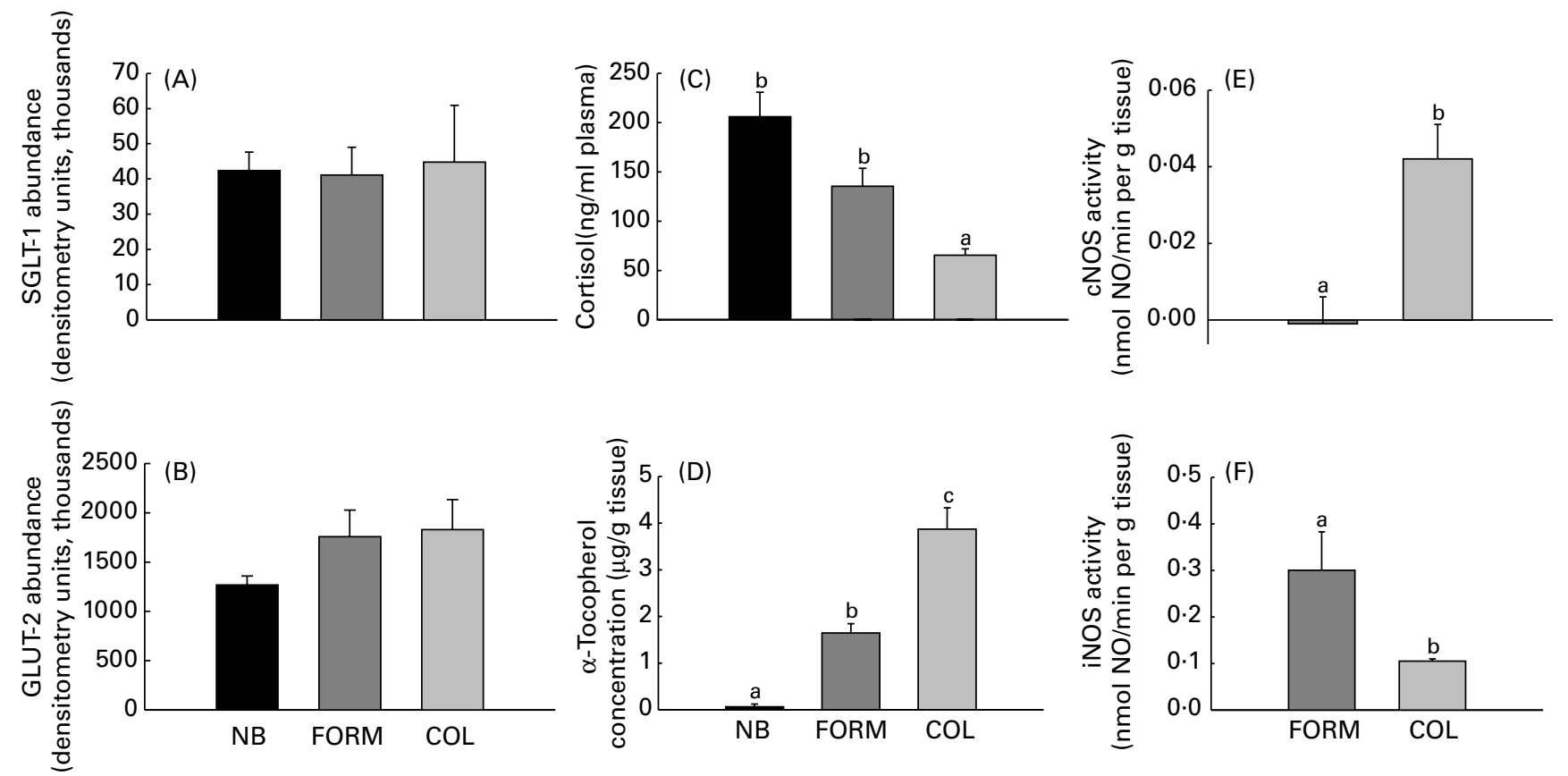

Fig. 3. Small-intestinal abundance of sodium GLUT-1 (SGLT-1; A) and GLUT-2 (B), plasma cortisol (C), small-intestinal $\alpha$-tocopherol concentration (D), constitutive NO synthase (CNOS) activity (E) and inducible NO synthase (iNOS) activity (F) in neonatal pigs. Values are means, with their standard errors represented by vertical bars ( $(4-6)$. NB, newborn control; FORM, formula-fed; COL, colostrum-fed. ${ }^{\text {a,b,c }}$ Mean values with unlike letters were significantly different $(P<0.05)$. 


\section{Acknowledgements}

Mette H. Schmidt and Anna Sierkierska, of Royal Veterinary and Agricultural University, Denmark, Liwei Hui, of Children's Nutrition Research Center, Houston, and Elsebeth Lyng Pedersen, of the Danish Institute of Agricultural Sciences, are greatly acknowledged for their skilful handling of surgical and laboratory procedures. The present study was financially supported by the Danish Agricultural and Veterinary Research Council. A preliminary account of the data has been published elsewhere (Nielsen et al. 2003).

\section{References}

Argenzio RA \& Meuten DJ (1991) Short-chain fatty acids induce reversible injury of porcine colon. Dig Dis Sci 36, 1459-1468.

Blood J, Ingle AR, Allison N, Davis GR \& Hill PG (1991) Rapid enzymatic method for the measurement of mannitol in urine. Ann Clin Biochem 28, 401-406.

Guan X, Stoll B, Lu X, Tappenden KA, Holst JJ, Hartmann B \& Burrin DG (2003) GLP-2-mediated up-regulation of intestinal blood flow and glucose uptake is nitric oxide-dependent in TPNfed piglets. Gastroenterology 125, 136-147.

Jensen AR, Elnif J, Burrin DG \& Sangild PT (2001) Development of intestinal immunoglobulin absorption and enzyme activities in neonatal pigs is diet dependent. $J$ Nutr 131, 3259-3265.

Jensen SK, Engberg RM \& Hedemann MS (1999) All-rac- $\alpha$-tocopherol acetate is a better vitamin $\mathrm{E}$ source than all-rac- $\alpha$-tocopherol succinate for broilers. $J$ Nutr 129, 1355-1360.

Kaempf JW, Battaglia FC \& Sparks JW (1990) Galactose clearance and carbohydrate metabolism across the gastrointestinal tract in the newborn lamb. Metabolism 39, 698-703.

Kien CL (1996) Digestion, absorption, and fermentation of carbohydrates in the newborn. Clin Perinatol 23, 211-228.

Kien CL, Liechty EA, Myerberg DZ \& Mullett MD (1987) Dietary carbohydrate assimilation in the premature infant: evidence for a nutritionally significant bacterial ecosystem in the colon. Am J Clin Nutr 46, 456-460.

Kubes P (2000) Inducible nitric oxide synthase: a little bit of good in all of us. Gut 47, 6-9.

Kubes P \& McCafferty DM (2000) Nitric oxide and intestinal inflammation. Am J Med 109, 150-158.

Kurz G \& Wallenfels K (1974) D-Galactose UV assay with galactose dehydrogenase. In Methods of Enzymatic Analysis, 2nd ed., pp. 1279-1282 [HU Bergmeyer, editor]. New York: Academic Press.

Lauridsen C, Engel H, Jensen SK, Craig AM \& Traber MG (2003) Lactating sows and suckling piglets preferentially incorporate RRR- over all-rac- $\alpha$-tocopherol into milk, plasma and tissues. J Nutr 132, 1258-1264.

Lucas A \& Cole TJ (1990) Breast milk and neonatal necrotizing enterocolitis. Lancet 336, 1519-1523.

McGuire W \& Anthony MY (2003) Donor human milk versus formula for preventing necrotising enterocolitis in preterm infants: systematic review. Arch Dis Child 88, 11-14.

Mahan DC (1991) Assessment of the influence of dietary vitamin E on sows and offspring in three parities: reproductive performance, tissue tocopherol, and effects on progeny. J Anim Sci 69, 2904-2917.
Neu J (1996) Necrotizing enterocolitis: the search for a unifying pathogenic theory leading to prevention. Pediatr Clin $N \mathrm{Am} \mathrm{43}$, 409-432.

Nielsen TT, Bjornvad CR \& Sangild PT (2003) Newborn pigs fed milk replacer show reduced lactose digestive capacity without effects on intestinal morphology and enzyme activity. In Proceedings of the 9th International Symposium on Digestive Physiology in Pigs, vol. 2, pp. 158-161. [RO Ball and R Ball, editors]. Banff, Canada: University of Alberta.

Sangild PT, Bjornvad CR, Petersen YM, Elnif J \& Burrin DG (2002a) Spontaneous NEC-like symptoms in formula-fed premature pigs. Gastroenterology 122, Suppl., A341.

Sangild PT, Fowden AL \& Trahair JF (2000) How does the foetal gastrointestinal tract develop in preparation for enteral nutrition after birth? Livestock Prod Sci 66, 141-150.

Sangild PT, Harrison AP, Nielsen TT \& Bjornvad CR (2003) Neonatal maturation of intestinal motility and structure is dietdependent. In Proceedings of the 9th International Symposium on Digestive Physiology in Pigs, vol. 2, pp. 155-157 [RO Ball and R Ball, editors]. Banff, Canada: University of Alberta.

Sangild PT, Petersen YM, Schmidt M, Elnif J, Petersen TK, Buddington RK, Greisen G, Michaelsen KF \& Burrin DG (2002b) Preterm birth affects the intestinal response to parenteral and enteral nutrition in newborn pigs. $J$ Nutr 132, 3786-3794.

Sangild PT, Sjostrom H, Noren O, Fowden AL \& Silver M (1995) The prenatal development and glucocorticoid control of brushborder hydrolases in the pig small intestine. Pediatr Res 37, 207-212.

Sangild PT \& Xu RJ (2004) Colostrum. In Encyclopedia of Animal Science, pp. 1-3 [WG Pond and AW Bell, editors]. New York: Marcel Dekker.

Sangild PT, Xu RJ \& Trahair JF (2002c) Maturation of intestinal function: the role of birth and cortisol. In Biology of the Small Intestine in Growing Animals, pp. 111-144 [R Zabielski, $\mathrm{V}$ Lesnewski, BR Weström and SR Pierzynowski, editors]. Amsterdam: Elsevier.

Stoll B, Burrin DG, Henry J, Yu H, Jahoor F \& Reeds PJ (1999) Substrate oxidation by the portal drained viscera of fed piglets. Am J Physiol 277, E168-E175.

Stoll B, Henry J, Reeds PJ, Yu H, Jahoor F \& Burrin DG (1998) Catabolism dominates the first-pass intestinal metabolism of dietary essential amino acids in milk protein-fed piglets. J Nutr 128, 606-614.

Tappenden KA \& McBurney MI (1998) Systemic short-chain fatty acids rapidly alter gastrointestinal structure, function, and expression of early response genes. Dig Dis Sci 43, 1526-1536.

Trahair JF \& Sangild PT (1997) Systemic and luminal influences on the perinatal development of the gut. Equine Vet J 24, Suppl., $40-50$.

Watkins JB (1982) Developmental aspects of carbohydrate malabsorption in the premature infant. In Carbohydrate Intolerance in Infancy (Clinical Disorders in Pediatric Nutrition), pp. 61-73 [F Lifshitz, editor]. New York: Marcel Dekker.

Wu G, Flynn NE, Flynn SP, Jolly CA \& Davis PK (1999) Dietary protein or arginine deficiency impairs constitutive and inducible nitric oxide synthesis by young rats. $J$ Nutr 129, $1347-1354$.

Zang H, Malo C, Boyle CR \& Buddington RK (1998) Diet influences development of the pig (Sus scrofa) intestine during the first 6 hours after birth. J Nutr 128, 1302-1310. 